\title{
Editorial
}

\section{LEPROSY CONTROL IN ETHIOPIA}

In this number of Leprosy Review, we present a leading article by a highly experienced group of research workers on dapsone resistance in Ethiopia, and combine this with other contributions on the subject of leprosy and the health services, in a part of Africa which has been described (Schaller, 1972) as "unmatched among the tropical countries as far as abundance of pathology is concerned".

In addition to this abundance of pathology, the physical character of the country itself presents formidable problems, many of which are described in detail in a volume on Ethiopia in the remarkable Geomedical Monograph Series, published by Springer-Verlag, Berlin (1972), and from which we extract information on leprosy in this number by Professor K. F. Schaller, Director of the Ernst Rodenwald Institute in Koblenz and Chairman of the Medical Commission of ILEP. Ethiopia has a population of about 24 million, of whom only 2 million live in cities, most of the registered leprosy patients occupying the central, hilly areas (Cap and Mulatu, 1976). The number recorded as having been registered is in itself a matter of concern; in the Weekly Epidemiological Record of January 1979, WHO estimate 135,000 cases of leprosy for Ethiopia, of whom only 59,000 are registered. The lepromatous rate is given as $50 \%$ - an unusually high figure for Africa.

Clearly this means that well under half the estimated cases have been registered and that amongst the unregistered (and therefore presumably untreated) cases, no fewer than $50 \%$ may be excreting bacilli into the envirorment, mainly - as numerous contributions to this and other journals in recent years have confirmed-from the nose and nasal mucus.

These sombre facts on the leprosy control situation in a large country where roads, communications, government and medical services have never been well developed, must now be considered in the context of several years' political chaos and bloodshed, as yet by no means resolved. Even when all the fighting is over, the course of events in some other African countries suggests that Ethiopia may take a long time to make a medical recovery, and it would be unrealistic to expect that leprosy will be given a high priority in this process. Elsewhere in this issue, $\operatorname{Dr}$ A. P. Oomen (Amsterdam) draws on his long experience of Ethiopia in reviewing some of the achievements-and the setbacks, of health manpower training.

In his account of this disease, published in 1972, Professor K. F. Schaller ref ers to "vast areas of Ethiopia where leprosy represents a major problem, with which the country will be conf ronted for many years to come". On top of all the difficulties he had in mind, we now have to face the increasingly welldocumented fact of resistance to dapsone, for which Dr J. M. H. Pearson and 
his colleagues present further evidence in the following pages. Although most of their patients were drawn from the Addis Ababa area, it is noteworthy that they include cases from elsewhere in the country, 28 of them being proved resistant by mouse foot-pad tests. Their conclusion that dapsone resistance is now "so widespread in Ethiopia as to threaten the practical possibility of leprosy control by chemotherapy alone", is, to say the least, disquieting. Taken with their previously published work on dapsone resistance in Malaysia, it surely points-as WHO have indeed already stressed - to the urgency of further investigating the whole matter, not only in Ethiopia, but in other countries of the world where dapsone has been used in low dosage, and irregularly, over a period of years. One thinks immediately of India, with its own estimate of 3.2 million cases of leprosy, as a country from which data on dapsone resistance, from large groups of treated and untreated patients, would be of the utmost value.

Meanwhile, we have to consider the most advantageous use of the drugs available, and in the Correspondence section of this number, Dr Harold Wheate, Director of Training at ALERT in Addis Ababa, stresses the importance of looking for dapsone resistance in the large pool of registered patients who have received dapsone, often inadequately and irregularly for many years, suggesting a suitable regimen of drug treatment for them. This is accompanied by a reply from Dr R. J.W. Rees in which he draws attention to the additional grim possibilities of resistance to rifampicin or thiosemicarbazone (thiacetazone) under certain circumstances in relapsed cases.

In view of these therapeutic difficulties in leprosy, together with the limited number of drugs available and the practical problems of distributing them regularly and for long enough to a significant percentage of those estimated to suffer from the disease, many will consider that the facts call for even further impetus towards the development of a vaccine. While this is in progress, it looks as if more information about dapsone resistance, scientifically based on mouse-foot-pad techniques, or perhaps on a radioactive assay, such as that described by Ambrose and his colleagues in 1978, must be obtained by other investigators from as many countries as possible. It will then be possible to assess with greater accuracy the relative importance of the two factors upon which the strategy - and the cost —of leprosy control probably depends most vitally - (1) the large numbers of patients estimated by WHO to be unregistered and therefore untreated (amongst which there are some countries with disturbingly high lepromatous rates), and (2) the extent of primary and secondary dapsone resistance in the world.

A. C. MCDOUGALL

\section{References}

Ambrose, E. J., Khanolkar, S. R. and Chulawalla, R. G. (1978). A rapid test for bacillary resistance to dapsone. Lepr. India 50, 131. (Reviewed in Abstracts of Lepr. Rev. 50 (1979) by $\operatorname{Dr}$ M. F. R. Waters.)

Cap, J. A. and Mulatu, B. (1976). La lèpre en Ethiopie; situation actuelle. Med. Trop. 36, 11.

Schaller, K. F. (1972). Leprosy in Ethiopia; a Geomedical Monograph, pp. 114-116. SpringerVerlag, Berlin, Heidelberg, New York.

WHO (1979). Leprosy. Wkly Epidem. Rec. No. 3, 17. 